$$
\begin{array}{ll}
\text { Preprints are preliminarar reports that have not undergone peer review. } \\
\text { They hould not be considered conclusive, used to inform clinical practice, } \\
\text { or referenced by the media as validated information. }
\end{array}
$$

\title{
Integrative Effects of Stress- and Stress Tolerance-Inducing Elicitors on In Vitro Bioactive Compounds of Ajowan (Trachyspermum Ammi (L.) Sprague) Medicinal Plant
}

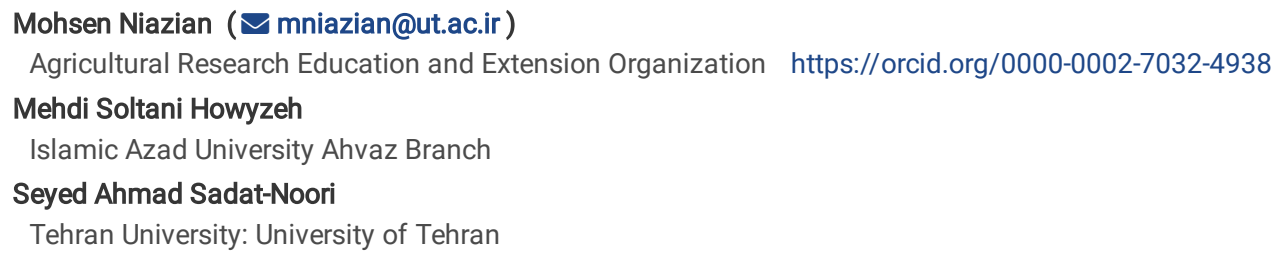

\section{Research Article}

Keywords: Antioxidants, Bioactive compounds, Elicitor, Indirect shoot, Secondary metabolites, Stress

Posted Date: February 15th, 2021

DOI: https://doi.org/10.21203/rs.3.rs-229057/v1

License: @ (i) This work is licensed under a Creative Commons Attribution 4.0 International License. Read Full License 


\section{Abstract}

Bioactive compounds of medicinal plants have a wide range of applications in pharmaceutical, food and other industries. In vitro culture systems have great potential for sustainable production of bioactive compounds of medicinal plants. In the present study, the individual and combined effects of a stress tolerance-inducing (salicylic acid) and a stress-inducing elicitor (polyethylene glycol) were evaluated on regeneration efficiency, antioxidants activity and phytochemical profile of in vitro shoot cultures of ajowan. Different concentrations of salicylic acid (SA) $(0,10,20,40,80 \mu \mathrm{M})$ and polyethylene glycol (PEG $6000)(0,1,2,5 \%)$ were added to the shoot regeneration Murashige and Skoog medium containing Kin (1.5 mg/L) and NAA (0.25 mg/L) plant growth regulators. Salicylic acid reduced the adverse effect of PEG treatment on number of regenerated shoots and in vitro rooting. The activities of catalase, superoxide dismutase, and peroxidase enzymatic antioxidants were significantly increased in SA + PEG treated plants. The gas chromatography-mass spectrometry (GC-MS)-profiling revealed quantitative and qualitative phytochemical differences between control and SA + PEG treated plants. The greatest means of $p$-cymene and thymol bioactive compounds were obtained from in vitro shoots treated with $5 \%$ PEG $+40 \mu M$ SA. The inter-simple sequence repeats (ISSR) markers proved the genetic stability of in vitro regenerated plants. The presented protocol is useful for large-scale sustainable production of secondary metabolites (SMs) of medicinal plants. The same strategy (stress tolerance-inducing elicitor + stress-inducing elicitor) is applicable to increase valuable SMs in other production systems such as hydroponic, greenhouse and field conditions.

\section{Introduction}

There is an increasing demand for plant-derived natural products, especially the bioactive compounds of medicinal plants (Niazian et al. 2018; Soltani Howyzeh et al. 2019). These bioactive compounds are the basis for many commercial pharmaceutical drugs and have great values in pharmaceutical, food, perfume, agrochemical, cosmetic and other industries ( $\mathrm{Li}$ et al. 2020). Therefore, finding efficient protocols for sustainable production of bioactive compounds of medicinal plants, including secondary metabolites (SMs), is very important to meet the growing demands in pharmaceutical and other industries.

Environmental factors such as drought, salinity, light intensity, high/low temperature, heavy metals and soil nutrients status have adverse effects on plant growth and photosynthesis. Osmolytes accumulation, antioxidants production and higher SMs accumulation are some of the plant responses to harsh environmental conditions (Mahajan et al. 2020). Secondary metabolites are chemical defense molecules that secreted when plants are under biotic and abiotic stresses (Alvarado et al. 2019). Improving growth and survival of plants under stressful conditions is the primary function of SMs (Khare et al. 2020). Stress induction and/or defense machine stimulation are two practical strategies to increase the accumulation of plants defense molecules, mainly antioxidant SMs. Due to environmental, geographical and seasonal independency, in vitro culture systems have great potential to increase the accumulation of plant's bioactive compounds in a sustainable manner (Chandran et al. 2020). In vitro culture systems provide controlled conditions for quantitative and qualitative alteration of SMs of medicinal plants. Different stress-inducing materials and defense-trigger biotic and abiotic elicitors can be easily added to the culture medium and stimulate the accumulation of SMs in different in vitro culture systems of medicinal plants. Polyethylene glycol (PEG), NaCl and heavy metal ions are examples of such stress-inducing compounds. Adding cadmium chloride $\left(\mathrm{CdCl}_{2}\right)$ to the culture medium increased alliin content in in vitro cultures of garlic (Allium sativum) (Malik et al. 2020) and plumbagin in the callus culture of chitrak (Plumbago zeylanica L.) (Singh et al. 2020). The accumulation of secondary metabolites of shikimic acid, caffeic acid, p-coumaric acid and rosmarinic acid was increased significantly in the cell suspension culture of Salvia miltiorrhiza by adding $50 \mathrm{mmol} / \mathrm{L}$ of $\mathrm{NaCl}$ to the culture medium (Yu et al. 2019). The positive effect of PEG 6000 (4\%) on the total phenolic content, total flavonoid content and total antioxidant capacity of shoot cultures of Stevia rebaudiana has been reported (Ahmad et al. 2020). Applying elicitors, which stimulate the plant stress response (defense-trigger elicitors), is another important strategy in in vitro culture system. Stress hormones (signaling compounds), including abscisic acid, jasmonic acid, methyl jasmonate, and salicylic acid (SA), are the most important group of elicitors that have been applied to improve SMs accumulation in medicinal plants in vitro cultures (Thakur et al., 2019). Application of salicylic acid (1.0 mg/L) resulted in a significant increase in bacoside content in cell suspension culture of Bacopa monnieri (Koul and Mallubhotla 2020).

Ajowan (Trachyspemum ammi L.) is one of the valuable medicinal plants of the Apiaceaefamily. Ajowan seeds have essential oil that contains about $50 \%$ of thymol. Thymol is a valuable bioactive compound with strong germicide, anti-spasmodic and fungicidal effects (Niaizian et al. 2018). Different in vitro-based methods, including artificial tetraploidy induction (Noori et al. 2017), genetic engineering (Niazian et al. 2019; Nomani et al. 2019), and biotic-abiotic elicitation (Razavizadeh et al. 2020), have been applied to improve the valuable bioactive compounds of ajowan. The present study was conducted to evaluate the effect of SA elicitation on regeneration efficiency, enzymatic antioxidants activity and secondary metabolite production in shoot cultures of ajowan under the artificially induced drought stress (PEG 6000).

\section{Materials And Methods}

\section{Plant material and indirect regeneration procedure}

Fifteen days old in vitro-obtained hypocotyl segments of Shiraz ecotype of ajowan were used as initial explants for callus induction in Murashige and Skoog (MS) medium supplemented with $0.2 \mathrm{mg} / \mathrm{L}$ naphthalene acetic acid (NAA) and $1.5 \mathrm{mg} / \mathrm{L}$ 6-benzylaminopurine (BAP). Callus induction of established hypocotyls was initiated after 15 days and three rounds of subcultures were done in the same medium. For shoot regeneration, induced calli were transferred to MS medium supplemented with $1.5 \mathrm{mg} / \mathrm{L}$ of Kin plus $0.25 \mathrm{mg} / \mathrm{L}$ NAA. The complete details of indirect shoot regeneration procedure of ajowan have been elaborated in Niazian et al (2017).

\section{Elicitation of in vitro cultures}

Combination of different concentrations of salicylic acid (SA) $(0,10,20,40,80 \mu \mathrm{M})$ and PEG $6000(0,1,2$ and $5 \%)$ were used to assess the effect of concomitant use of artificially induced drought stress and elicitation on enzymatic antioxidants and bioactive compounds of in vitro regenerated shoots of 
ajowan. The MS medium containing Kin (1.5 mg/L), NAA (0.25 mg/L), 3\% (w/v) sucrose and 0.7\% (w/v) agar (pH 5.8) was used as control. Culture medium was autoclaved at $121^{\circ} \mathrm{C}$ for $20 \mathrm{~min}$ and then filter-sterilized $(0.2 \mu \mathrm{m}) \mathrm{SA}$ and PEG were added to medium under the laminar airflow chamber. Five callus segments were cultured in petri dishes containing $30 \mathrm{~mL}$ of MS medium supplemented with different combinations of PEG and SA. Experiment was arranged as factorial, based on a completely randomized design (CRD), with three replications (as petri dishes). All cultures were kept in a phytotron with $16 / 8 \mathrm{~h}$ (light/dark) photoperiod, photosynthetic photon flux density (PPFD) of $40 \mu \mathrm{mol} \mathrm{m}^{-2} \mathrm{~s}^{-1}$, and $24^{\circ} \mathrm{C}$. Subcultures were done with two weeks intervals and the combined effect of treatments on the number of regenerated shoots was investigated in the seventh week of the experiment.

For root induction, the regenerated shoots were transferred to half strength plant growth regulator (PGR)-free MS medium. Culture vessels were maintained in a phytotron with aforementioned condition for the shoot regeneration. The combined effect of PEG and SA on rooting of in vitro regenerated shoots was evaluated after two weeks.

\section{Acclimatization}

The well-developed roots $(\sim 3 \mathrm{~cm})$ of regenerated plants were first washed with distilled sterile water to remove the traces of agar. Then, plantlets were transferred to plastic pots containing 1: 1 perlite: cucurbit. The pots were covered with transparent plastic and irrigated with half strength MS medium for one week and then covers were removed for complete acclimatization. The successfully acclimatized plantlets were then transferred to plastic pots $(8 \times 10 \mathrm{~cm})$ filled with autoclaved farm soil. The greenhouse established plants were grown and after two months starts to flowering. In the next two months, reached seeds were gathered and used for essential oil extraction and phytochemical assessments.

\section{Measurement Of Enzymatic Antioxidants}

Fresh leaf samples protein was extracted by Sudhakar et al. (2001) method. The activity of catalase (CAT) enzyme was measured using Aebi (1974) method. The activity of peroxidase (POX) was estimated using Hemeda and Klein (1990) method. Superoxide dismutase (SOD) activity was measured using Beauchamp and Fridovich (1971) method.

\section{Essential oil extraction and gas chromatography mass spectrometry (GC-MS) analysis}

For essential oil extraction, a seed sample (20g), consist of a mixture of three plants from each group of in vitro regenerated plants, was ground using an electric grinder, then achieved fine powder was added to $500 \mathrm{~mL}$ distilled water on top of a heater at $100^{\circ} \mathrm{C}$ and oil was extracted using a Clevenger-type 5 apparatus (Noori et al. 2017) for 2.5h. Essential oil extraction was conducted in three replications. For GC-MS, $1 \mu \mathrm{L}$ of the essential oil samples was injected into the GC split-less with the injection port. The GC-MS analysis was conducted in three replications. A GC-MS apparatus using the HP (Agilent Technology): 6890 Network GC System gas chromatograph connected to a mass detector (5973 Network Mass Selective Detector) was used for GC-MS analysis. The gas chromatograph was equipped with an HP-5MS capillary column (fused silica column, $30 \mathrm{~m} \times 0.25 \mathrm{~mm}$ i.d., Agilent Technologies) and an El mode with ionization energy of $70 \mathrm{eV}$ with a scan time of $0.4 \mathrm{~s}$ and mass range of $40-460 \mathrm{amu}$ was used. Helium gas was a carrier and its flow rate was $1.0 \mathrm{ml} / \mathrm{min}$. The oven temperature was linearly programmed from 40 to $250^{\circ} \mathrm{C}$ at a rate of $3^{\circ} \mathrm{C} / \mathrm{min}$. The composition of the essential oil constituents was identified based on the comparison of their retention time relative to n-alkanes and computer matching with the NIST (National Institute of Standards and Technology) Adams library spectra, Wiley 7 n.1 mass computer library, and with those reported in literature (Adams 1997). In the final, area under the curve of GC/MS spectra was used to calculate the relative percentage of each component (Soltani Howyzeh et al. 2018; Noori et al. 2017).

Genetic stability assessment using inter simple sequence repeats (ISSR) markers

To assess the genetic stability of in vitro regenerated plants different DNA samples from regenerated plants, each group contains mixed DNAs of leaves of ten plants (three weeks old), were used to assess the genetic stability. The DNA extraction was done using a CTAB-activated charcoal protocol described by Križman et al (2006). Ten UBC primers of Set \#9 (University of British Columbia, Vancouver, Canada) were used as ISSR markers. The PCR amplifications were carried out using a C-1000 thermal cycler (Bio-Rad, Hercules, USA) following the protocol described by Rawat et al. (2013). PCR amplified products were separated through an agarose gel (1.5\%) in 0.5X TBE buffer stained with ethidium bromide under $100 \mathrm{~V}$ constant power supply for $1.5 \mathrm{~h}$ and visualized under UV light in gel documentation system (Cleaver Scientific Ltd., Rugby, UK).

\section{Statistical analysis}

All statistical analyses of the present study, including analysis of variance (ANOVA) and means comparison analysis, were conducted using SAS ${ }^{\circledR}$ software (SAS Institute Inc., Cary, NC). The normality test was conducted with SAS software before the analysis of variance. The Duncan's multiple ranges test (DMRT) at a $5 \%(P \leq 0.05)$ probability level was used for the means comparisons analysis.

\section{Results}

\section{Indirect shoot regeneration and rooting of regenerated shoots under the effect of PEG and SA elicitors}

Proliferated calli were obtained in MS medium supplemented with NAA $(0.2 \mathrm{mg} / \mathrm{L})$ and BAP $(1.5 \mathrm{mg} / \mathrm{L})$ at the end of the second week of the experiment (Fig. 1a). Induced calli were then transferred to shoot induction medium. The first regenerated shoots were observed on MS medium containing NAA ( 0.25 $\mathrm{mg} / \mathrm{L}$ ) and Kin (1.5 mg/L) PGRs along with combinations of PEG and SA (Fig. 1b). Regenerated shoots showed visual symptoms of wilting in culture medium containing PEG treatment (Fig. 1c). The results of means comparison analysis, using DMRT at 5\% probability level, showed a significant decrease in the 
number of regenerated shoots with increasing concentrations of PEG in culture medium (Fig. 2a). The greatest mean of number of regenerated shoots was observed in control treatment (MS medium containing NAA and Kin PGRs), whereas, the lowest regenerated shoots was obtained in MS medium containing highest concentration of PEG (5\%) and SA $(80 \mu \mathrm{M})$. (Fig. 2a). At a certain concentration of PEG, SA treatment caused a significant increase in the number of regenerated shoots (Fig. 2a). The regenerated shoots were transferred to the root induction medium (Fig. 3a). Developed roots were observed after two weeks of establishment in PGR-free MS medium (Fig. 3b). The results of means comparison analysis revealed the significant adverse effect of PEG on root induction percentage of in vitro regenerated shoots of ajowan. The lowest rooting percentage was obtained by the highest degree of drought stress (5\% PEG 6000$)$ (Fig. 2b). The greatest rooting percentage was obtained in control treatment. Salicylic acid showed positive effect on rooting percentage of PEG-treated shoots as the greatest mean of rooting percentage under severe drought stress (5\% PEG 6000) was obtained by using $40 \mu \mathrm{M}$ of SA (Fig. $2 \mathrm{~b}$ ).

\section{Antioxidative enzymes activity under the effects of PEG and SA elicitors}

A substantial increase in CAT activity was observed with increasing levels of PEG and SA in shoot induction medium (Table 1). The greatest mean of CAT activity was observed in shoots regenerated in MS medium containing highest concentrations of applied PEG $6000(5 \%)$ and SA (80 $\mu \mathrm{M})$. Under the severe artificial drought stress (5\% PEG), there was no significant difference between 40 and $80 \mu \mathrm{M}$ of SA, based on the DMRT test (Table 1). The highest levels of PEG 6000 and SA significantly increased the SOD activity (Table 1). The lowest mean of the SOD activity of in vitro regenerated shoots of ajowan observed when $1 \%$ of PEG 6000 along with $10 \mu \mathrm{M}$ SA were added to the regeneration medium (Table 1). The highest POX activity was observed at severe artificial drought stress, whereas the lowest activity was observed in control treatment. Salicylic acid under PEG treatment induced a significant increase in POX activity (Table 1). In non-stress condition ( $0 \%$ PEG), SA treatment increased activity of POX, however, there was no significant difference between applied concentrations of SA at the $5 \%$ probability level (Table 1$)$.

Table 1

Effect of in vitro drought stress and salicylic acid elicitor on the catalase, superoxide dismutase and peroxidase activity in indirect regenerated shoots of ajowan. Induced calli were cultured on MS medium containing $0.25 \mathrm{mg} / \mathrm{L}$ NAA and $1.5 \mathrm{mg} / \mathrm{L}$ Kin along with combinations of PEG6000 (0, $1,2,5 \%)$ and

$\begin{array}{lllll}\begin{array}{l}\text { PEG } 6000 \\ \text { concentration }(\%)\end{array} & \begin{array}{l}\text { Salicylic acid } \\ \text { concentration }\end{array} & \begin{array}{l}\text { Catalase (unit mg-1 } \\ \text { protein) }\end{array} & \begin{array}{l}\text { Superoxide dismutase (unit mg } \\ \text { protein) }\end{array} & \begin{array}{l}\text { Peroxidase (unit mg protein } \\ \left.\text { min }^{-1}\right)\end{array} \\ & (\mu \mathrm{M}) & & \end{array}$

\begin{tabular}{|c|c|c|c|c|}
\hline \multirow[t]{5}{*}{0} & 0 & $0.56 \pm 0.02^{m}$ & $127.33 \pm 0.27^{g}$ & $0.40 \pm 0.00^{1}$ \\
\hline & 10 & $0.766 \pm 0.11^{1}$ & $125.67 \pm 1.66^{g}$ & $0.52 \pm 0.02^{k}$ \\
\hline & 20 & $0.766 \pm 0.01^{1}$ & $130.67 \pm 0.66^{g}$ & $0.57 \pm 0.00^{k}$ \\
\hline & 40 & $0.81 \pm 0.01^{\mathrm{kl}}$ & $133.00 \pm 0.57^{g}$ & $0.65 \pm 0.01^{j}$ \\
\hline & 80 & $1.03 \pm 0.03^{\mathrm{ij}}$ & $131.67 \pm 0.88^{g}$ & $0.71 \pm 0.00^{\mathrm{ij}}$ \\
\hline \multirow[t]{5}{*}{1} & 0 & $0.93 \pm 0.03^{\mathrm{jk}}$ & $135.33 \pm 1.66^{\mathrm{g}}$ & $0.74 \pm 0.00^{i}$ \\
\hline & 10 & $0.88 \pm 0.01^{j-1}$ & $97.33 \pm 3.66^{h}$ & $0.75 \pm 0.00^{\mathrm{hi}}$ \\
\hline & 20 & $0.93 \pm 0.03^{\mathrm{jk}}$ & $138.67 \pm 0.88^{f-g}$ & $0.78 \pm 0.00^{g-i}$ \\
\hline & 40 & $1.13 \pm 0.03^{i}$ & $143.00 \pm 1.00^{e-g}$ & $0.76 \pm 0.01^{\mathrm{hi}}$ \\
\hline & 80 & $1.33 \pm 0.12^{h}$ & $145.67 \pm 0.66^{e-g}$ & $0.76 \pm 0.02^{\mathrm{hi}}$ \\
\hline \multirow[t]{5}{*}{2} & 0 & $1.46 \pm 0.03^{g h}$ & $148.33 \pm 0.33^{d-g}$ & $0.82 \pm 0.00^{f-h}$ \\
\hline & 10 & $1.53 \pm 0.03^{g}$ & $150.67 \pm 0.66^{c-g}$ & $0.84 \pm 0.02^{e-g}$ \\
\hline & 20 & $1.60 \pm 0.00^{\mathrm{fg}}$ & $153.00 \pm 0.00^{c-g}$ & $0.87 \pm 0.00^{e f}$ \\
\hline & 40 & $1.71 \pm 0.01^{\text {ef }}$ & $167.00 \pm 0.010^{b-f}$ & $0.88 \pm 0.00^{e f}$ \\
\hline & 80 & $1.78 \pm 0.01^{\mathrm{de}}$ & $171.00 \pm 1.00^{\mathrm{b}-\mathrm{e}}$ & $0.90 \pm 0.00^{e}$ \\
\hline \multirow[t]{5}{*}{5} & 0 & $1.86 \pm 0.03^{\mathrm{cd}}$ & $175.67 \pm 0.33^{b-d}$ & $1.06 \pm 0.03^{d}$ \\
\hline & 10 & $1.93 \pm 0.03^{b c}$ & $179.33 \pm 0.33^{\mathrm{bc}}$ & $1.13 \pm 0.03^{d}$ \\
\hline & 20 & $2.03 \pm 0.03^{b}$ & $186.67 \pm 1.66^{b}$ & $1.26 \pm 0.03^{c}$ \\
\hline & 40 & $2.33 \pm 0.08^{a}$ & $240.00 \pm 0.00^{a}$ & $1.433 \pm 0.06^{b}$ \\
\hline & 80 & $2.46 \pm 0.03^{a}$ & $245.00 \pm 2.88^{a}$ & $1.733 \pm 0.03^{a}$ \\
\hline
\end{tabular}

Values represent the mean + standard error of three biological replicates. Values followed by the same letters are not significantly different at the $P<0.05$. 
The results of GC-MS analysis showed significant quantitative and qualitative differences in the composition of the essential oils of in vitro PEG and SA treated plants with plants regenerated in control medium (Fig. 4a,b). Thymol, $\mathrm{y}$-terpinene, and $p$-cymene were the main components in the essential oil of in vitro regenerated ajowan plants (Table 2). The major qualitative difference of in vitro regenerated plants was related to Sabinene that missed in the phytochemical profile of in vitro regenerated shoots treated with high levels of PEG 6000 (2\% and 5\%) (Table 2). The a-thujene percentage of non-treated plants was less than the PEG and SA treated shoots (Table 2).

Table 2

The phytochemical profile of in vitro regenerated plants of ajowan under the effects of drought stress and salicylic acid elicitor. Induced calli were cultured on I containing $0.25 \mathrm{mg} / \mathrm{L}$ NAA and $1.5 \mathrm{mg} / \mathrm{L}$ Kin along with combinations of PEG6000 $(0,1,2,5 \%)$ and salicylic acid $(0,10,20,40,80 \mu \mathrm{M})$ for indirect shoot reg

\begin{tabular}{|c|c|c|c|c|c|c|c|c|c|c|c|}
\hline $\begin{array}{l}\text { PEG } 6000 \\
\text { concentration } \\
\text { (\%) }\end{array}$ & $\begin{array}{l}\text { Salicylic acid } \\
\text { concentration } \\
(\mu \mathrm{M})\end{array}$ & $\stackrel{a-}{\text { Thujene }}$ & $\begin{array}{l}\text { a- } \\
\text { Pinene }\end{array}$ & Sabinene & $\begin{array}{l}\beta- \\
\text { Pinene }\end{array}$ & $\begin{array}{l}\beta- \\
\text { Myrcene }\end{array}$ & $\begin{array}{l}\text { a- } \\
\text { Terpinene }\end{array}$ & $\begin{array}{l}\text { p- } \\
\text { Cymene }\end{array}$ & $\begin{array}{l}\beta- \\
\text { Phellandrene }\end{array}$ & Y- & $\begin{array}{l}\text { Terpinene- } \\
\text { 4-ol }\end{array}$ \\
\hline \multirow[t]{5}{*}{0} & 0 & $\begin{array}{l}0.21 \pm \\
0.00^{k}\end{array}$ & $\begin{array}{l}0.10 \pm \\
0.00^{\mathrm{b}}\end{array}$ & $\begin{array}{l}0.22 \pm \\
0.01^{\mathrm{a}}\end{array}$ & $\begin{array}{l}1.32 \pm \\
0.00^{k}\end{array}$ & $\begin{array}{l}0.67 \pm \\
0.01^{h}\end{array}$ & $\begin{array}{l}0.64 \pm \\
0.00^{1}\end{array}$ & $\begin{array}{l}16.40 \pm \\
0.00^{\prime}\end{array}$ & $0.22 \pm 0.00^{n}$ & $\begin{array}{l}27.48 \pm \\
6.65^{\mathrm{b}}\end{array}$ & $\begin{array}{l}0.36 \pm \\
0.00^{1}\end{array}$ \\
\hline & 10 & $\begin{array}{l}0.23 \pm \\
0.00^{\mathrm{ij}}\end{array}$ & $\begin{array}{l}0.13 \pm \\
0.00^{\mathrm{b}}\end{array}$ & $\begin{array}{l}0.18 \pm \\
0.00^{\mathrm{ab}}\end{array}$ & $\begin{array}{l}1.25 \pm \\
0.02\end{array}$ & $\begin{array}{l}0.67 \pm \\
0.00^{\mathrm{h}}\end{array}$ & $\begin{array}{l}0.65 \pm \\
0.00^{k}\end{array}$ & $\begin{array}{l}16.43 \pm \\
0.02^{1}\end{array}$ & $\begin{array}{l}0.23 \pm \\
0.00^{\mathrm{mn}}\end{array}$ & $\begin{array}{l}34.12 \pm \\
0.06^{a}\end{array}$ & $\begin{array}{l}0.36 \pm \\
0.00^{1}\end{array}$ \\
\hline & 20 & $\begin{array}{l}0.22 \pm \\
0.01^{\mathrm{jk}}\end{array}$ & $\begin{array}{l}0.52 \pm \\
0.39^{a}\end{array}$ & $\begin{array}{l}0.22 \pm \\
0.01^{\mathrm{a}}\end{array}$ & $\begin{array}{l}1.36 \pm \\
0.00^{\mathrm{jk}}\end{array}$ & $\begin{array}{l}0.69 \pm \\
0.00^{9}\end{array}$ & $\begin{array}{l}0.66 \pm \\
0.01^{j}\end{array}$ & $\begin{array}{l}16.53 \pm \\
0.03^{k}\end{array}$ & $0.24 \pm 0.00^{\mathrm{lm}}$ & $\begin{array}{l}34.24 \pm \\
0.02^{a}\end{array}$ & $\begin{array}{l}0.37 \pm \\
0.00^{\mathrm{kl}}\end{array}$ \\
\hline & 40 & $\begin{array}{l}0.24 \pm \\
0.00^{\mathrm{hi}}\end{array}$ & $\begin{array}{l}0.15 \pm \\
0.00^{b}\end{array}$ & $\begin{array}{l}0.21 \pm \\
0.01^{\mathrm{ab}}\end{array}$ & $\begin{array}{l}1.38 \pm \\
0.00^{\mathrm{ij}}\end{array}$ & $\begin{array}{l}0.71 \pm \\
0.00^{f}\end{array}$ & $\begin{array}{l}0.68 \pm \\
0.01^{i}\end{array}$ & $\begin{array}{l}16.62 \pm \\
0.05^{j}\end{array}$ & $0.24 \pm 0.00^{\mathrm{kl}}$ & $\begin{array}{l}34.34 \pm \\
0.03^{a}\end{array}$ & $\begin{array}{l}0.36 \pm \\
0.00^{\mathrm{kl}}\end{array}$ \\
\hline & 80 & $\begin{array}{l}0.24 \pm \\
0.00^{\mathrm{hi}}\end{array}$ & $\begin{array}{l}0.15 \pm \\
0.00^{\mathrm{b}}\end{array}$ & $\begin{array}{l}0.19 \pm \\
0.04^{\mathrm{ab}}\end{array}$ & $\begin{array}{l}1.41 \pm \\
0.01^{\mathrm{hi}}\end{array}$ & $\begin{array}{l}0.72 \pm \\
0.00^{f}\end{array}$ & $\begin{array}{l}0.68 \pm \\
0.00^{i}\end{array}$ & $\begin{array}{l}16.69 \pm \\
0.01^{\mathrm{ij}}\end{array}$ & $0.25 \pm 0.00^{k}$ & $\begin{array}{l}34.44 \pm \\
0.02^{a}\end{array}$ & $\begin{array}{l}0.36 \pm \\
0.00^{\mathrm{kl}}\end{array}$ \\
\hline \multirow[t]{5}{*}{1} & 0 & $\begin{array}{l}0.24 \pm \\
0.00^{\mathrm{h}}\end{array}$ & $\begin{array}{l}0.18 \pm \\
0.00^{b}\end{array}$ & $\begin{array}{l}0.17 \pm \\
0.01^{\mathrm{bc}}\end{array}$ & $\begin{array}{l}1.56 \pm \\
0.01^{\mathrm{cd}}\end{array}$ & $\begin{array}{l}0.73 \pm \\
0.01^{\mathrm{e}}\end{array}$ & $\begin{array}{l}0.68 \pm \\
0.00^{i}\end{array}$ & $\begin{array}{l}16.70 \pm \\
0.00^{\mathrm{ij}}\end{array}$ & $0.26 \pm 0.00^{j}$ & $\begin{array}{l}35.03 \pm \\
0.03^{\mathrm{a}}\end{array}$ & $\begin{array}{l}0.38 \pm \\
0.00^{\mathrm{ij}}\end{array}$ \\
\hline & 10 & $\begin{array}{l}0.25 \pm \\
0.00^{h}\end{array}$ & $\begin{array}{l}0.18 \pm \\
0.00^{\mathrm{b}}\end{array}$ & $\begin{array}{l}0.17 \pm \\
0.01^{\mathrm{bc}}\end{array}$ & $\begin{array}{l}1.59 \pm \\
0.00^{c}\end{array}$ & $\begin{array}{l}0.74 \pm \\
0.00^{e}\end{array}$ & $\begin{array}{l}0.71 \pm \\
0.00^{h}\end{array}$ & $\begin{array}{l}16.72 \pm \\
0.01^{i}\end{array}$ & $0.26 \pm 0.00^{\mathrm{ij}}$ & $\begin{array}{l}35.01 \pm \\
0.01^{a}\end{array}$ & $\begin{array}{l}0.37 \pm \\
0.00^{\mathrm{jk}}\end{array}$ \\
\hline & 20 & $\begin{array}{l}0.26 \pm \\
0.00^{g}\end{array}$ & $\begin{array}{l}0.19 \pm \\
0.00^{\mathrm{b}}\end{array}$ & $\begin{array}{l}0.13 \pm \\
0.01^{\mathrm{cd}}\end{array}$ & $\begin{array}{l}1.43 \pm \\
0.01^{g} \\
-i\end{array}$ & $\begin{array}{l}0.73 \pm \\
0.00^{\mathrm{e}}\end{array}$ & $\begin{array}{l}0.71 \pm \\
0.00^{h}\end{array}$ & $\begin{array}{l}16.82 \pm \\
0.01^{h}\end{array}$ & $0.27 \pm 0.00^{i}$ & $\begin{array}{l}35.05 \pm \\
0.03^{a}\end{array}$ & $\begin{array}{l}0.38 \pm \\
0.00^{\mathrm{ij}}\end{array}$ \\
\hline & 40 & $\begin{array}{l}0.27 \pm \\
0.00^{f g}\end{array}$ & $\begin{array}{l}0.20 \pm \\
0.00^{b}\end{array}$ & $\begin{array}{l}0.10 \pm \\
0.03^{d}\end{array}$ & $\begin{array}{l}1.43 \pm \\
0.01^{g} \\
-i\end{array}$ & $\begin{array}{l}0.74 \pm \\
0.00^{e}\end{array}$ & $\begin{array}{l}0.71 \pm \\
0.00^{h}\end{array}$ & $\begin{array}{l}16.85 \pm \\
0.02^{h}\end{array}$ & $0.28 \pm 0.00^{h}$ & $\begin{array}{l}35.13 \pm \\
0.02^{\mathrm{a}}\end{array}$ & $\begin{array}{l}0.39 \pm \\
0.00^{i}\end{array}$ \\
\hline & 80 & $\begin{array}{l}0.28 \pm \\
0.00^{f}\end{array}$ & $\begin{array}{l}0.20 \pm \\
0.00^{b}\end{array}$ & $\begin{array}{l}0.04 \pm \\
0.04^{\mathrm{e}}\end{array}$ & $\begin{array}{l}1.47 \pm \\
0.00^{f g}\end{array}$ & $\begin{array}{l}0.76 \pm \\
0.00^{d}\end{array}$ & $\begin{array}{l}0.72 \pm \\
0.00^{\mathrm{h}}\end{array}$ & $\begin{array}{l}16.90 \pm \\
0.00^{h}\end{array}$ & $0.29 \pm 0.00^{\mathrm{h}}$ & $\begin{array}{l}35.30 \pm \\
0.07^{a}\end{array}$ & $\begin{array}{l}0.40 \pm \\
0.00^{\mathrm{h}}\end{array}$ \\
\hline \multirow[t]{5}{*}{2} & 0 & $\begin{array}{l}0.31 \pm \\
0.00^{\mathrm{e}}\end{array}$ & $\begin{array}{l}0.25 \pm \\
0.00^{\mathrm{ab}}\end{array}$ & - & $\begin{array}{l}1.43 \pm \\
0.00^{g h}\end{array}$ & $\begin{array}{l}0.78 \pm \\
0.00^{c}\end{array}$ & $\begin{array}{l}0.77 \pm \\
0.00^{g}\end{array}$ & $\begin{array}{l}17.07 \pm \\
0.03^{\mathrm{g}}\end{array}$ & $0.31 \pm 0.00^{g}$ & $\begin{array}{l}35.33 \pm \\
0.01^{a}\end{array}$ & $\begin{array}{l}0.41 \pm \\
0.00^{g}\end{array}$ \\
\hline & 10 & $\begin{array}{l}0.32 \pm \\
0.00^{\mathrm{e}}\end{array}$ & $\begin{array}{l}0.25 \pm \\
0.01^{\mathrm{ab}}\end{array}$ & - & $\begin{array}{l}1.45 \pm \\
0.01^{\mathrm{gh}}\end{array}$ & $\begin{array}{l}0.78 \pm \\
0.01^{c}\end{array}$ & $\begin{array}{l}0.78 \pm \\
0.00^{f}\end{array}$ & $\begin{array}{l}17.14 \pm \\
0.01^{f g}\end{array}$ & $0.32 \pm 0.00^{\mathrm{g}}$ & $\begin{array}{l}35.51 \pm \\
0.13^{a}\end{array}$ & $\begin{array}{l}0.41 \pm \\
0.00^{f g}\end{array}$ \\
\hline & 20 & $\begin{array}{l}0.33 \pm \\
0.00^{d}\end{array}$ & $\begin{array}{l}0.26 \pm \\
0.00^{\mathrm{ab}}\end{array}$ & - & $\begin{array}{l}1.50 \pm \\
0.00^{\text {ef }}\end{array}$ & $\begin{array}{l}0.78 \pm \\
0.00^{c}\end{array}$ & $\begin{array}{l}0.78 \pm \\
0.00^{f}\end{array}$ & $\begin{array}{l}17.19 \pm \\
0.00^{\text {ef }}\end{array}$ & $0.33 \pm 0.00^{f}$ & $\begin{array}{l}35.92 \pm \\
0.08^{a}\end{array}$ & $\begin{array}{l}0.42 \pm \\
0.00^{\text {ef }}\end{array}$ \\
\hline & 40 & $\begin{array}{l}0.35 \pm \\
0.00^{c}\end{array}$ & $\begin{array}{l}0.27 \pm \\
0.00^{\mathrm{ab}}\end{array}$ & - & $\begin{array}{l}1.52 \pm \\
0.00^{\mathrm{de}}\end{array}$ & $\begin{array}{l}0.80 \pm \\
0.00^{b}\end{array}$ & $\begin{array}{l}0.81 \pm \\
0.00^{\mathrm{e}}\end{array}$ & $\begin{array}{l}17.20 \pm \\
0.00^{\text {ef }}\end{array}$ & $0.35 \pm 0.01^{e}$ & $\begin{array}{l}36.09 \pm \\
0.04^{\mathrm{a}}\end{array}$ & $\begin{array}{l}0.42 \pm \\
0.00^{\text {ef }}\end{array}$ \\
\hline & 80 & $\begin{array}{l}0.36 \pm \\
0.00^{\mathrm{b}}\end{array}$ & $\begin{array}{l}0.28 \pm \\
0.00^{\mathrm{ab}}\end{array}$ & - & $\begin{array}{l}1.55 \pm \\
0.01^{\mathrm{cd}}\end{array}$ & $\begin{array}{l}0.84 \pm \\
0.00^{\mathrm{a}}\end{array}$ & $\begin{array}{l}0.82 \pm \\
0.00^{d}\end{array}$ & $\begin{array}{l}17.23 \pm \\
0.01^{\mathrm{de}}\end{array}$ & $0.38 \pm 0.01^{d}$ & $\begin{array}{l}36.22 \pm \\
0.05^{a}\end{array}$ & $\begin{array}{l}0.43 \pm \\
0.00^{\mathrm{e}}\end{array}$ \\
\hline \multirow[t]{5}{*}{5} & 0 & $\begin{array}{l}0.39 \pm \\
0.00^{\mathrm{a}}\end{array}$ & $\begin{array}{l}0.32 \pm \\
0.00^{\mathrm{ab}}\end{array}$ & - & $\begin{array}{l}1.75 \pm \\
0.03^{\mathrm{a}}\end{array}$ & $\begin{array}{l}0.66 \pm \\
0.00^{\mathrm{h}}\end{array}$ & $\begin{array}{l}0.88 \pm \\
0.00^{c}\end{array}$ & $\begin{array}{l}17.30 \pm \\
0.00^{d}\end{array}$ & $0.40 \pm 0.00^{c}$ & $\begin{array}{l}36.46 \pm \\
0.01^{a}\end{array}$ & $\begin{array}{l}0.46 \pm \\
0.00^{d}\end{array}$ \\
\hline & 10 & $\begin{array}{l}0.38 \pm \\
0.01^{a}\end{array}$ & $\begin{array}{l}0.33 \pm \\
0.00^{\mathrm{ab}}\end{array}$ & - & $\begin{array}{l}1.60 \pm \\
0.00^{c}\end{array}$ & $\begin{array}{l}0.65 \pm \\
0.00^{i}\end{array}$ & $\begin{array}{l}0.89 \pm \\
0.00^{\mathrm{bc}}\end{array}$ & $\begin{array}{l}17.43 \pm \\
0.01^{\mathrm{c}}\end{array}$ & $0.40 \pm 0.00^{c}$ & $\begin{array}{l}36.57 \pm \\
0.01^{a}\end{array}$ & $\begin{array}{l}0.47 \pm \\
0.01^{\mathrm{cd}}\end{array}$ \\
\hline & 20 & $\begin{array}{l}0.38 \pm \\
0.01^{\mathrm{a}}\end{array}$ & $\begin{array}{l}0.35 \pm \\
0.00^{\mathrm{ab}}\end{array}$ & - & $\begin{array}{l}1.57 \pm \\
0.00^{c}\end{array}$ & $\begin{array}{l}0.64 \pm \\
0.01^{\mathrm{ij}}\end{array}$ & $\begin{array}{l}0.91 \pm \\
0.00^{\mathrm{a}}\end{array}$ & $\begin{array}{l}18.04 \pm \\
0.03^{b}\end{array}$ & $0.42 \pm 0.00^{\mathrm{b}}$ & $\begin{array}{l}37.00 \pm \\
0.00^{\mathrm{a}}\end{array}$ & $\begin{array}{l}0.47 \pm \\
0.00^{c}\end{array}$ \\
\hline & 40 & $\begin{array}{l}0.38 \pm \\
0.00^{a}\end{array}$ & $\begin{array}{l}0.36 \pm \\
0.00^{\mathrm{ab}}\end{array}$ & - & $\begin{array}{l}1.66 \pm \\
0.04^{\mathrm{b}}\end{array}$ & $\begin{array}{l}0.63 \pm \\
0.00^{\mathrm{jk}}\end{array}$ & $\begin{array}{l}0.89 \pm \\
0.00^{\mathrm{bc}}\end{array}$ & $\begin{array}{l}18.19 \pm \\
0.03^{a}\end{array}$ & $0.42 \pm 0.00^{b}$ & $\begin{array}{l}37.10 \pm \\
0.00^{a}\end{array}$ & $\begin{array}{l}0.51 \pm \\
0.01^{\mathrm{a}}\end{array}$ \\
\hline & 80 & $\begin{array}{l}0.36 \pm \\
0.00^{\mathrm{b}}\end{array}$ & $\begin{array}{l}0.39 \pm \\
0.01^{\mathrm{ab}}\end{array}$ & - & $\begin{array}{l}1.55 \pm \\
0.01^{\mathrm{cd}}\end{array}$ & $\begin{array}{l}0.62 \pm \\
0.01^{\mathrm{k}}\end{array}$ & $\begin{array}{l}0.90 \pm \\
0.00^{\mathrm{ab}}\end{array}$ & $\begin{array}{l}17.47 \pm \\
0.07^{c}\end{array}$ & $0.44 \pm 0.00^{a}$ & $\begin{array}{l}37.46 \pm \\
0.01^{\mathrm{a}}\end{array}$ & $\begin{array}{l}0.49 \pm \\
0.00^{\mathrm{b}}\end{array}$ \\
\hline
\end{tabular}

Values represent the mean + standard error of three biological replicates. Values followed by the same letters are not significantly different at the $P<0.05$. 
Based on the results of GC-MS analysis, $p$-cymene of in vitro micropropagated plants was increased with increasing levels of PEG and SA (Table 2). The greatest mean of $p$-cymene was observed when $5 \%$ PEG along with $40 \mu \mathrm{M}$ of SA were added to the shoot induction medium (Table 2). Another major component of essential oil, $\gamma$-terpinene, in PEG and SA treated shoots was more than the control plants, however, there were no significant differences among applied PEG and SA concentrations in terms of this bioactive compound (Table 2). The combination of PEG and SA had a significant positive effect on the amount of thymol. The greatest mean of thymol content (53.15\%) was obtained with the application of SA ( $40 \mu \mathrm{M})$ under severe drought stress treatment (5\% $\mathrm{PEG}$ ). The lowest mean of the thymol content was obtained in plants regenerated under control treatment (Table 2).

\section{Genetic Stability Assessment}

Ten amplified ISSR primers produced 115 scorable bands from in vitro regenerated plant of ajowan in control and SA-PEG treated media. An average of 11 bands per primer, ranging from 7 to 13 bands, with only $2.45 \%$ of polymorphism was observed (Fig. 5).

\section{Discussion}

The plant cell/tissue/organ culture is one of the promising biotechnology-based breeding methods (BBBMs) for constant production of SMs of medicinal plants (Niazian 2019). The traditional (adding different components such as PGRs, precursors, elicitors and other additives to the culture medium) in vitro techniques are simpler and cost-effective than complicate BBBMs, such as genetic engineering and synthetic biology.

Differentiated (organogenesis) and undifferentiated (callus) culture systems have been applied for in vitro production of the bioactive compounds of medicinal plants. Callus cultures have great potential for sustainable production of bioactive compounds of medicinal plants (Koufan et al. 2020). However, undifferentiated calluses are not as promising as organogenesis cultures in terms of SMs production (Santos et al. 2020). The superiority of differentiated cultures over the callus culture systems, in terms of level of produced bioactive compounds, has been reported in Schisandra henryi (Jafernik et al. 2020), Phellodendron chinense (He et al. 2020) and Argania spinosa (L.) (Koufan et al. 2020). These observations could be due to the effect of developmental factors on SMs of medicinal plants, as the major of secondary metabolites often occur at a certain stage of plant growth. In addition, there is a relationship between the morphogenesis and the synthesis and accumulation of SMs in medicinal plants (Li et al. 2020).

The application of biotic and abiotic elicitors in culture medium, which induce defense-related metabolic pathways, is one the creative strategies to change the biochemical profile of medicinal plants and enhance the accumulation of valuable antioxidant bioactive compounds (Liu et al. 2018; Mahendran et al. 2018; Tonk et al. 2016). Elicitors are a group of plant biostimulants, in two biotic and abiotic forms, which their application in in vitro cultures at different stages can increase the volume of defensive secondary compounds of medicinal plants (Tonk et al. 2016). Stress hormones (SA, abscisic acid, jasmonic acid, methyl jasmonate), compatible solutes (proline), chitosan, and microbial extracts (bacterial, fungal and yeast) are the most applied biotic elicitors. There are also some abiotic elicitors that can be added to the culture medium for direct stress induction, especially osmotic stress. Polyethylene glycol, NaCl, heavy metal ions and nanoparticles-based metals are examples of abiotic stress-inducing elicitors.

In the present study, the combined effect of a stress-inducing abiotic elicitor and stress signal molecule of SA was assessed on the SMs and enzymatic antioxidants activity of ajowan shoot cultures. Applied PEG significantly reduced the number of regenerated shoots and rooting percentage of the regenerated shoots. Salicylic acid treatment compensated for the negative effects of artificially induced drought stress on shoot regeneration and rooting of regenerated shoots and increased the regeneration efficiency of ajowan under stressful conditions. However, the greatest means of regenerated shoots and rooting percentage were related to the control medium. Miclea et al (2020) have reported the adverse effect of elicitors on number of in vitro shoots in Lavandula angustifolia. Salicylic acid is a stress tolerance-inducing compound that can improve plants growth under stressful conditions via modulation of the physiological parameters, reactive oxygen species (ROS) scavenging capacity, phytohormonal changes and antioxidant enzyme activity (Abdelaal et al. 2020; Rasheed et al. 2020; Torun et al. 2020). The positive effects of SA and PEG on SMs content and antioxidants activity of in vitro regenerated shoots were evident in the present study. Thymol and $p$-cymene considerably increased under the artificially induced drought stress and SA treatment. Salicylic acid is a signaling molecule that involved in the expression of stress-related genes in plant cells and the secretion of SMs in stress conditions induced by abiotic or biotic factors (Demirci et al. 2021). Therefore, to increase the accumulation of secondary metabolites, the use of salicylic acid under stressful conditions can be much more effective than its use in non-stressful conditions. Researchers have mainly applied the above mentioned biotic and abiotic elicitors individually in in vitro cultures of different medicinal plants. However, there are some examples of the combined use of these elicitors. Razavizadeh et al (2020) applied different concentrations of chitosan $(0,10$ and $20 \mathrm{mg} / \mathrm{L})$ in callus and shoot cultures of ajowan, under artificially induced salinity stress ( $\mathrm{NaCl})$, and reported the positive effect of $\mathrm{NaCl}$ and chitosan in enhancing the contents of thymol and $p$-cymene. They also reported the increased activity of CAT, SOD and ascorbate peroxidase antioxidants under in vitro induced salt stress (100 mM NaCl). The integrative application of biotic (chitosan and SA) and abiotic ( $\mathrm{NaCl}$ ) elicitors led to enhanced total phenolics and total flavonoids in callus cultures of safflower (Carthamus tinctorius L.) (Golkar et al. 2019). Karamian et al (2020) investigated the effect of in vitro methyl jasmonate elicitor on bioactive compounds of Verbascum sinuatum under drought stress (PEG 6000) condition. They reported that the highest total phenol and flavonoid contents were obtained when $200 \mu \mathrm{M}$ of methyl jasmonate was added to the culture medium under severe drought stress $(-0.5 \mathrm{MPa})$.

In addition to the stress tolerance-inducing elicitors, stress tolerance-enhancer compounds, such as melatonin, have been applied as elicitors to increase the accumulation of in vitro bioactive components of medicinal plants (Coskun et al. 2019; Duran et al. 2019). Other stress tolerance-enhancer additives, such as gibberelin inhibitors, ethylene inhibitors, osmoprotectants, antioxidant activators, ROS scavengers, and detoxification activators (Niazian and Shariatpanahi 2020), can potentially be used in combination with stress-inducing elicitors (PEG, NaCl, heavy metal ions) to increase the in vitro production of plants bioactive compounds. Silver nitrate $\left(\mathrm{AgNO}_{3}\right)$, as an ethylene inhibitor compound, has been applied to increase bioactive compounds of medicnal plants in different in 
vitro culture systems (Gonçalves et al. 2019; Yu et al. 2019; Açıkgöz 2020). It is obvious the integrative application of these stress tolerance-enhancers and stress-inducing elicitors can be more effective than their individually application in terms of accumulation of antioxidant SMs.

Finding the best combination(s) of defense-trigger biotic and abiotic elicitors is very important to achieving the maximum levels of desired bioactive compounds of medicinal plants in different in vitro culture systems. However, in vitro culture is a multi-variable procedure with many influential factors. There are some useful advanced computational methods, such as machine learning algorithms, that can help researchers to overcome the complex nature of in vitro studies (Hesami et al. 2020; Hesami and Jones 2020; Niazian and Niedbała 2020). These advanced computational methods have also been applied for modeling and optimizing in vitro production of plant's bioactive compounds, under the effect of various influencing factors (Kaur et al. 2020; Salehi et al. 2020; Salehi et al. 2021).

Monomorphic patterns of ISSR primers showed no genetic variation between control and in vitro regenerated plants under the effect of applied elicitors. Production of genetic clones of the true-too-type plants is the main objective of an in vitro regeneration program. However, obtained plants from an indirect organogenesis pathway usually show slight divergence in genetic composition (Kshirsagar et al. 2021). Therefore, assessing the genetic fidelity of regenerated plants is an essential step in establishing an efficient protocol for the in vitro production of SMs of medicinal plants. Researchers often use molecular markers and flow cytometry to study the genetic stability of in vitro regenerated shoots. ISSR markers cover different genomic regions and offer an effective method for evaluating somaclonal variation in regenerated plants (Rawat et al. 2018; Raji and Farajpour 2020). While preserving the genetics of the in vitro regenerants, the optimized protocol in the present study increased the accumulation of valuable bioactive compounds of ajowan medicinal plant using integrated SA-PEG biotic and abiotic elicitors. This protocol can be widely used for the sustainable and safe production of SMs of other medicinal plants of Apiaceae family.

\section{Conclusions}

In vitro culture systems provide an excellent opportunity for the sustainable production of valuable bioactive compounds of medicinal plants. Precursor feeding, elicitation and manipulation of culture medium parameters (basal culture medium, PGRs, carbon sources, additives and pH) are the simple and efficient traditional methods to increase contents of in vitro SMs. Elicitation of culture systems with defense-trigger compounds is a creative strategy to stimulate the accumulation of defense SMs.

In the present study, stress tolerance-inducing SA and stress-inducing PEG were used together in indirect shoot regeneration of ajowan. Applied concentrations of SA reduced the adverse effects of PEG on shoot regeneration and rooting percentage of in vitro cultures. The co-application of SA and PEG led to the higher activity of enzymatic antioxidants (CAT, POX and SOD) and increased accumulation of valuable thymol and $p$-cymene bioactive compounds. Salicylic acid elicitation under artificially induced drought stress was more efficient than non-stress condition, in terms of in vitro production of SMs in ajowan medicinal plant. The results of the present study are useful for researchers who want to increase the amount of valuable bioactive compounds of their desired medicinal plants.

\section{Declarations}

\section{Acknowledgements}

The authors are thankful to the Research Institute of Forests and Rangelands of Iran for procuring the ajowan seeds.

\section{Authors' contribution}

MN performed in vitro and greenhouse experiments and wrote the whole body of manuscript. MSH contributed to study conception and project design, analysis and interpretation of data, GC/MS analysis, and revised the manuscript. SASN supervised the project and helped to improve the manuscript.

\section{Conflict of interest}

The authors declare that they have no conflicts of interest to disclose.

\section{Ethical standards}

There is no any ethical standard related to the present article.

\section{References}

Abdelaal KA, EL-Maghraby LM, Elansary H, Hafez YM, Ibrahim El, El-Banna M, El-Esawi M, Elkelish A (2020) Treatment of sweet pepper with stress toleranceinducing compounds alleviates salinity stress oxidative damage by mediating the physio-biochemical activities and antioxidant systems. Agronomy, 10(1), 26. https://doi.org/10.3390/agronomy10010026

Açıkgöz MA (2020) Establishment of cell suspension cultures of Ocimum basilicum L. and enhanced production of pharmaceutical active ingredients. Industrial Crops and Products, 148, 112278. https://doi.org/10.1016/j.indcrop.2020.112278

Adams RP (1997) Identification of essential oil components by gas chromatography/mass spectrometry. Allured Publication Corporation. Illinois-USA.

Aebi, H., 1974. Catalases. In: Bergmeyer HU (ed) Methods of enzymatic analysis. Academic Press, New York, 673-684. 
Ahmad MA, Javed R, Adeel M, Rizwan M, Yang Y (2020) PEG 6000-stimulated drought stress improves the attributes of in vitro growth, steviol glycosides production, and antioxidant activities in Stevia rebaudiana Bertoni. Plants, 9(11), 1552. https://doi.org/10.3390/plants9111552

Alvarado AM, Aguirre-Becerra H, Vázquez-Hernández MC, Magaña-Lopez E, Parola-Contreras I, Caicedo-Lopez LH, Contreras-Medina LM, Garcia-Trejo JF, Guevara-Gonzalez RG, Feregrino-Perez AA (2019) Influence of elicitors and eustressors on the production of plant secondary metabolites. In: Akhtar M., Swamy M., Sinniah U. (eds) Natural Bio-active Compounds. Springer, Singapore. https://doi.org/10.1007/978-981-13-7154-7_11

Beauchamp C, Fridovich I (1971) Superoxide dismutase: improved assay applicable to acrylamide gels. Ann Biochem 44, $276-287$.

Chandran H, Meena M, Barupal T, Sharma K (2020) Plant tissue culture as a perpetual source for production of industrially important bioactive compounds. Biotechnology Reports, e00450. https://doi.org/10.1016/j.btre.2020.e00450

Coskun Y, Duran RE, Kilic S (2019) Striking effects of melatonin on secondary metabolites produced by callus culture of rosemary (Rosmarinus officinalis L.). Plant Cell, Tissue and Organ Culture, 138(1), 89-95. https://doi.org/10.1007/s11240-019-01605-7

Demirci T, Ascı ÖA, Baydar NG (2021) Influence of salicylic acid and L-phenylalanine on the accumulation of anthraquinone and phenolic compounds in adventitious root cultures of madder (Rubia tinctorum L.). Plant Cell, Tissue and Organ Culture, 144, 313-324. https://doi.org/10.1007/s11240-020-01952-w

Duran RE, Kilic S, Coskun Y (2019) Melatonin influence on in vitro callus induction and phenolic compound production in sweet basil (Ocimum basilicum L.). In Vitro Cellular \& Developmental Biology-Plant, 55(4), 468-475. https://doi.org/10.1007/s11627-019-10006-6

Golkar P, Taghizadeh M, Yousefian Z (2019) The effects of chitosan and salicylic acid on elicitation of secondary metabolites and antioxidant activity of safflower under in vitro salinity stress. Plant Cell, Tissue and Organ Culture, 137(3), 575-585. https://doi.org/10.1007/s11240-019-01592-9

Gonçalves S, Mansinhos I, Rodríguez-Solana R, Pérez-Santín E, Coelho N, Romano A (2019) Elicitation improves rosmarinic acid content and antioxidant activity in Thymus lotocephalus shoot cultures. Industrial Crops and Products, 137, 214-220. https://doi.org/10.1016/j.indcrop.2019.04.071

He H, Qin J, Ma Z, Sun W, Yan W, He G, Yang M, Zhang D (2020) Highly efficient regeneration and medicinal component determination of Phellodendron chinense Schneid. In Vitro Cellular \& Developmental Biology-Plant, 56, 775-783. https://doi.org/10.1007/s11627-020-10080-1

Hemeda HM, Klein BP (1990) Effects of naturally occurring antioxidants on peroxidase activity of vegetable extracts. J. Food Sci. 55, 184-185.

Hesami M, Jones AMP (2020) Application of artificial intelligence models and optimization algorithms in plant cell and tissue culture. Applied Microbiology and Biotechnology, 1-37. https://doi.org/10.1007/s00253-020-10888-2

Hesami M, Naderi R, Tohidfar M, Yoosefzadeh-Najafabadi M (2020) Development of support vector machine-based model and comparative analysis with artificial neural network for modeling the plant tissue culture procedures: effect of plant growth regulators on somatic embryogenesis of chrysanthemum, as a case study. Plant Methods, 16(1), 1-15. https://doi.org/10.1186/s13007-020-00655-9

Jafernik K, Szopa A, Barnaś M, Dziurka M, Ekiert H (2020) Schisandra henryi CB Clarke in vitro cultures: a promising tool for the production of lignans and phenolic compounds. Plant Cell, Tissue and Organ Culture, 143(1), 45-60. https://doi.org/10.1007/s11240-020-01895-2

Karamian R, Ghasemlou F, Amiri H (2020) Physiological evaluation of drought stress tolerance and recovery in Verbascum sinuatum plants treated with methyl jasmonate, salicylic acid and titanium dioxide nanoparticles. Plant Biosystems-An International Journal Dealing with all Aspects of Plant Biology, 154(3), 277-287. https://doi.org/10.1080/11263504.2019.1591535

Kaur P, Gupta RC, Dey A, Malik T, Pandey DK (2020) Optimization of salicylic acid and chitosan treatment for bitter secoiridoid and xanthone glycosides production in shoot cultures of Swertia paniculata using response surface methodology and artificial neural network. BMC Plant Biology, 20, 1-13.

https://doi.org/10.1186/s12870-020-02410-7

Khare S, Singh NB, Singh A, Hussain I, Niharika K, Yadav V, Bano C, Yadav RK, Amist N (2020) Plant secondary metabolites synthesis and their regulations under biotic and abiotic constraints. Journal of Plant Biology, 63(3), 203-216. https://doi.org/10.1007/s12374-020-09245-7

Koufan M, Belkoura I, Mazri MA, Amarraque A, Essatte A, Elhorri H, Zaddoug F, Alaoui T (2020) Determination of antioxidant activity, total phenolics and fatty acids in essential oils and other extracts from callus culture, seeds and leaves of Argania spinosa (L.) Skeels. Plant Cell, Tissue and Organ Culture, 1-11. https://doi.org/10.1007/s11240-020-01782-w

Koul A, Mallubhotla S (2020) Elicitation and enhancement of bacoside production using suspension cultures of Bacopa monnieri (L.) Wettst. 3 Biotech, 10, 256. https://doi.org/10.1007/s13205-020-02242-0

Križman M, Jakše J, Baričevič D, Javornik B, Prošek M (2006) Robust CTAB-activated charcoal protocol for plant DNA extraction. Acta Agriculturae Slovenica, 87(2), 427-433.

Kshirsagar PR, Mohite A, Suryawanshi S, Chavan JJ, Gaikwad NB, Bapat VA (2021) Plant regeneration through direct and indirect organogenesis, phytomolecular profiles, antioxidant properties and swertiamarin production in elicitated cell suspension cultures of Swertia minor (Griseb.) Knobl. Plant Cell, Tissue and Organ Culture, 144, 383-396. https://doi.org/10.1007/s11240-020-01962-8 
Li Y, Kong D, Fu Y, Sussman MR, Wu H (2020) The effect of developmental and environmental factors on secondary metabolites in medicinal plants. Plant Physiology and Biochemistry, 148, 80-89. https://doi.org/10.1016/j.plaphy.2020.01.006

Liu ZB, Chen JG, Yin ZP, Shangguan XC, Peng DY, Lu T, Lin P (2018) Methyl jasmonate and salicylic acid elicitation increase content and yield of chlorogenic acid and its derivatives in Gardenia jasminoides cell suspension cultures. Plant Cell Tissue Organ Cult, https://doi.org/10.1007/s11240-018-1401-1.

Mahajan M, Kuiry R, Pal PK (2020) Understanding the consequence of environmental stress for accumulation of secondary metabolites in medicinal and aromatic plants. Journal of Applied Research on Medicinal and Aromatic Plants, 100255. https://doi.org/10.1016/j.jarmap.2020.100255

Mahendran D, Sreeramanan S, Venkatachalam P (2018) Enhanced biosynthesis of colchicine and thiocolchicoside contents in cell suspension cultures of Gloriosa superba L. exposed to ethylene inhibitor and elicitors. Ind Crops Prod, 120, 123-130. https://doi.org/10.1016/j.indcrop.2018.04.040

Malik MQ, Mujib A, Gulzar B, Zafar N, Syeed R, Mamgain J, Ejaz B (2020) Enrichment of alliin in different in vitro grown tissues of Allium sativum through $\mathrm{CdCl} 2$ elicitation as revealed by high performance thin layer chromatography (HPTLC). Industrial Crops and Products, $158,113007$. https://doi.org/10.1016/j.indcrop.2020.113007

Miclea I, Suhani A, Zahan M, Bunea A (2020) Effect of jasmonic acid and salicylic acid on growth and biochemical composition of in-vitro-propagated Lavandula angustifolia Mill. Agronomy, 10(11), 1722. https://doi.org/10.3390/agronomy10111722

Niazian M, Sadat Noori SA, Galuszka P, Tohidfar M, Mortazavian SMM (2017) Genetic stability of regenerated plants via indirect somatic embryogenesis and indirect shoot regeneration of Carum copticum L. Ind Crops Prod, 97: 330-337. http://dx.doi.org/10.1016/j.indcrop.2016.12.044

Niazian M, Sadat-Noori SA, Abdipour M (2018) Artificial neural network and multiple regression analysis models to predict essential oil content of ajowan (Carum copticum L.). J. App Res Med Arom Plants, 9, 124-131. https://doi.org/10.1016/j.jarmap.2018.04.001

Niazian M (2019) Application of genetics and biotechnology for improving medicinal plants. Planta, 249, 956-973. https://doi.org/10.1007/s00425-01903099-1

Niazian M, Sadat-Noori SA, Tohidfar M, Galuszka P, Mortazavian SMM (2019) Agrobacterium-mediated genetic transformation of ajowan (Trachyspermum ammi (L.) Sprague): an important industrial medicinal plant. Industrial Crops and Products, 132, 29-40. https://doi.org/10.1016/j.indcrop.2019.02.005

Niazian M, Niedbała G (2020) Machine learning for plant breeding and biotechnology. Agriculture, 10(10), 436. https://doi.org/10.3390/agriculture10100436

Niazian M, Shariatpanahi ME (2020) In vitro-based doubled haploid production: recent improvements. Euphytica, 216, 1-21. https://doi.org/10.1007/s10681020-02609-7

Nomani M, Noori SAS, Tohidfar M, Ramshini H (2019) Overexpression of TPS2 gene to increase thymol content using Agrobacterium tumefaciens-mediated transformation in Trachyspermum ammi (Qom ecotype). Industrial Crops and Products, 130, 63-70. https://doi.org/10.1016/j.indcrop.2018.12.076

Noori SA, Norouzi M, Karimzadeh G, Shirkool K, Niazian M (2017) Effect of colchicine-induced polyploidy on morphological characteristics and essential oil composition of ajowan (Trachyspermum ammi L.). Plant Cell Tissue Organ Cult, 130, 543-551. https://doi.org/10.1007/s11240-017-1245-0

Raji MR, Farajpour M (2020) Genetic fidelity of regenerated plants via shoot regeneration of muskmelon by inter simple sequence repeat and flow cytometry. Journal of the Saudi Society of Agricultural Sciences. https://doi.org/10.1016/j.jssas.2020.12.003

Rawat JM, Rawat B, Agnihotri RK, Chandra A, Nautiyal S (2013) In vitro propagation, genetic and secondary metabolite analysis of Aconitum violaceum Jacq.: a threatened medicinal herb. Acta physiol plant, 35(8), 2589-2599. https://doi.org/10.1007/s11738-013-1294-x

Rasheed F, Anjum NA, Masood A, Sofo A, Khan NA (2020) The key roles of salicylic acid and sulfur in plant salinity stress tolerance. Journal of Plant Growth Regulation, 1-14. https://doi.org/10.1007/s00344-020-10257-3

Rawat JM, Bhandari A, Mishra S, Rawat B, Dhakad AK, Thakur A, Chandra A (2018) Genetic stability and phytochemical profiling of the in vitro regenerated plants of Angelicaglauca Edgew.: an endangered medicinal plant of Himalaya. Plant Cell Tissue Organ Cult. https://doi.org/10.1007/s11240-018-1448-z

Razavizadeh R, Adabavazeh F, Komatsu S (2020) Chitosan effects on the elevation of essential oils and antioxidant activity of Carum copticum L. seedlings and callus cultures under in vitro salt stress. Journal of Plant Biochemistry and Biotechnology, 29(3), 473-483. https://doi.org/10.1007/s13562-020-00560-1

Salehi M, Farhadi S, Moieni A, Safaie N, Ahmadi H (2020) Mathematical modeling of growth and paclitaxel biosynthesis in Corylus avellana cell culture responding to fungal elicitors using multilayer perceptron-genetic algorithm. Frontiers in Plant Science, 11. https://dx.doi.org/10.3389\%2Ffpls.2020.01148

Salehi M, Farhadi S, Moieni A, Safaie N, Hesami M (2021) A hybrid model based on general regression neural network and fruit fly optimization algorithm for forecasting and optimizing paclitaxel biosynthesis in Corylus avellana cell culture. Plant Methods, 17(1), 1-13. https://doi.org/10.1186/s13007-021-00714-9

Santos GS, Sinoti SBP, de Almeida FTC, Silveira D, Simeoni LA, Gomes-Copeland KKP (2020) Use of galantamine in the treatment of Alzheimer's disease and strategies to optimize its biosynthesis using the in vitro culture technique. Plant Cell, Tissue and Organ Culture, 1-17. https://doi.org/10.1007/s11240-02001911-5 
Singh T, Sharma U, Agrawal V (2020) Isolation and optimization of plumbagin production in root callus of Plumbago zeylanica L. augmented with chitosan and yeast extract. Industrial Crops and Products, 151, 112446. https://doi.org/10.1016/j.indcrop.2020.112446

Soltani Howyzeh, M., Aslani, S., Pooraskari, O., 2019. Essential oil profile of an Iranian yarrow (Achilleamillefolium). J Essent Oil Bear Pl, 22, 295-300. https://doi.org/10.1080/0972060X.2019.1586589

Soltani Howyzeh M, Sadat Noori SA, Shariati V (2018) Essential oil profiling of Ajowan (Trachyspermumammi) industrial medicinal plant. Ind Crops Prod, 119, 255-259. https://doi.org/10.1016/j.indcrop.2018.04.022

Sudhakar C, Lakshmi A, Giridarakumar S (2001) Changes in the antioxidant enzyme efficacy in two high yielding genotypes of mulberry (Morus alba L.) under $\mathrm{NaCl}$ salinity. Plant Sci, 161(3), 613-619. https://doi.org/10.1016/S0168-9452(01)00450-2

Thakur M, Bhattacharya S, Khosla PK, Puri S (2019) Improving production of plant secondary metabolites through biotic and abiotic elicitation. Journal of Applied Research on Medicinal and Aromatic Plants, 12, 1-12. https://doi.org/10.1016/j.jarmap.2018.11.004

Tonk D, Mujib A, Maqsood M, Ali M, Zafar N (2016) Aspergillus flavus fungus elicitation improves vincristine and vinblastine yield by augmenting callus biomass growth in Catharanthus roseus. Plant Cell Tissue Organ Cult, 126(2), 291-303. https://doi.org/10.1007/s11240-016-0998-1

Torun H, Novák O, Mikulík J, Pěnčík A, Strnad M, Ayaz FA (2020) Timing-dependent effects of salicylic acid treatment on phytohormonal changes, ROS regulation, and antioxidant defense in salinized barley (Hordeum vulgare L.). Scientific Reports, 10(1), 1-17. https://doi.org/10.1038/s41598-020-70807-3

Yu Y, Wang T, Wu Y, Zhou Y, Jiang Y, Zhang L (2019) Effect of elicitors on the metabolites in the suspension cell culture of Salvia miltiorrhiza Bunge. Physiology and Molecular Biology of Plants, 25(1), 229-242. https://doi.org/10.1007/s12298-018-0605-5

\section{Figures}
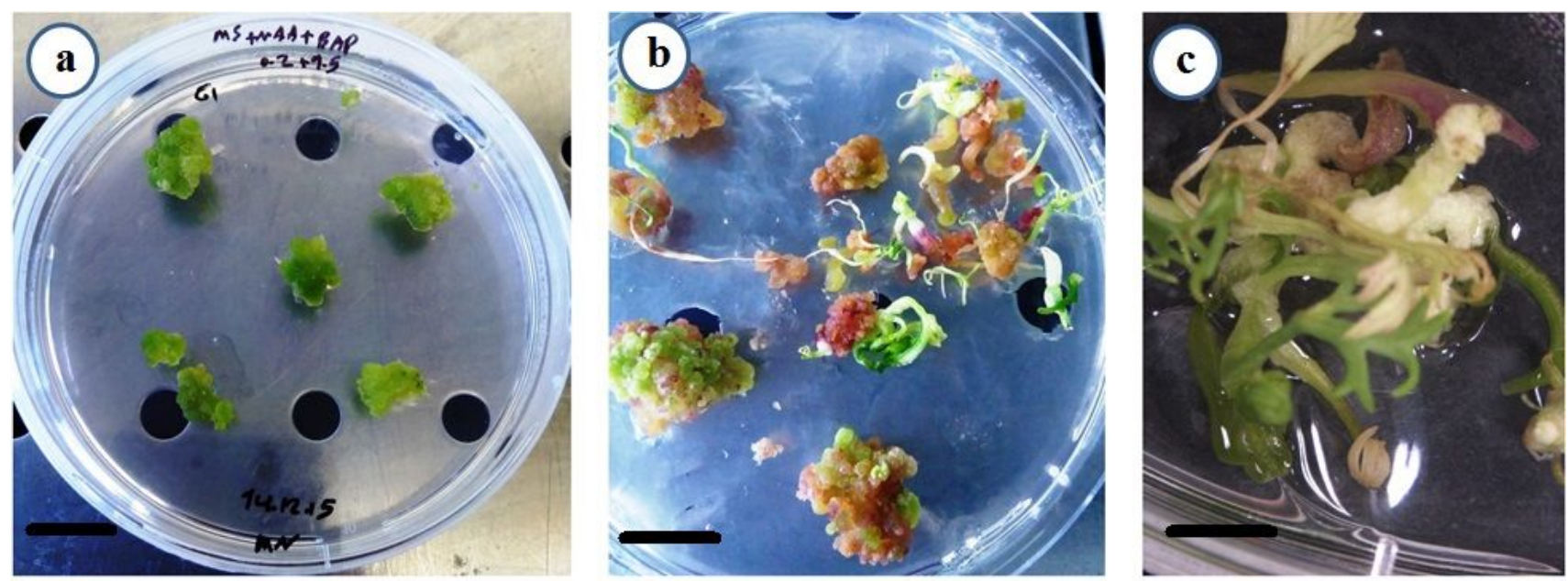

\section{Figure 1}

Indirect shoot regeneration of ajowan. (a) Callus induction in MS medium supplemented with $0.2 \mathrm{mg} / \mathrm{L}$ naphthalene acetic acid (NAA) and $1.5 \mathrm{mg} / \mathrm{L} 6$ benzylaminopurine (BAP) (bar=2cm). (b) Indirect shoot regeneration from induced calli in MS medium supplemented with $1.5 \mathrm{mg} / \mathrm{L}$ of Kin and $0.25 \mathrm{mg} / \mathrm{L} \mathrm{NAA}$ along with different combinations of PEG $(0,1,2,5 \%)$ and salicylic acid $(0,10,20,40,80 \mu \mathrm{M})(\mathrm{bar}=2 \mathrm{~cm})$. (c) The symptoms of wilting in shoots regenerated in culture medium containing PEG treatment (bar= $4 \mathrm{~mm})$. 

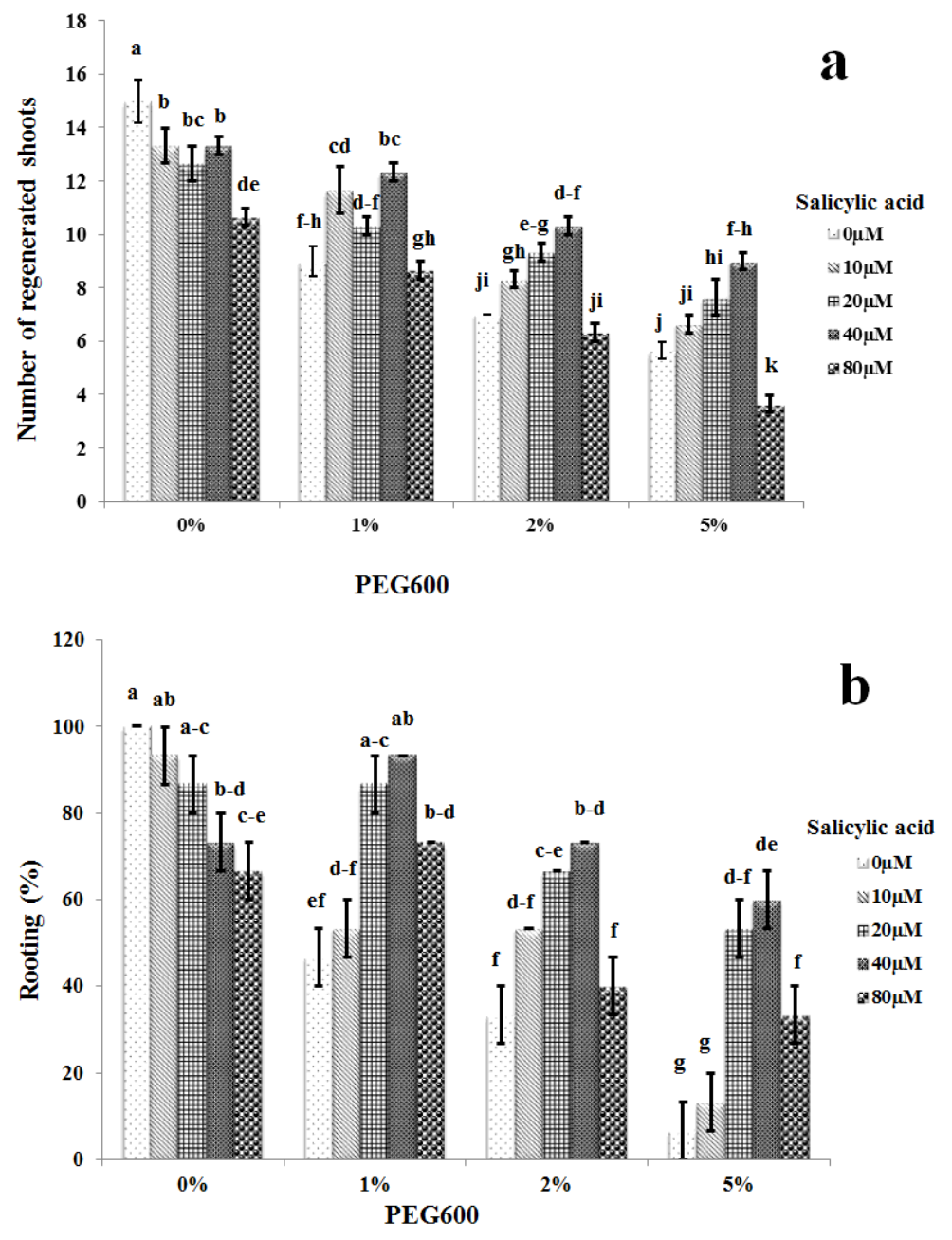

\section{Figure 2}

Effect of in vitro drought stress and salicylic acid elicitor on regeneration efficiency of ajowan. (a) The number of regenerated shoots under the effect of PEG and salicylic acid elicitors. (b) Rooting percentage of regenerated shoots under the effect of PEG and salicylic acid elicitors. Different combinations of PEG (0, $1,2,5 \%)$ and salicylic acid $(0,10,20,40,80 \mu \mathrm{M})$ elicitors were added to the indirect regeneration medium (MS medium supplemented with $1.5 \mathrm{mg} / \mathrm{L}$ of Kin and $0.25 \mathrm{mg} / \mathrm{L} \mathrm{NAA}$ ). Values followed by the same letters are not significantly different at the $\mathrm{P}<0.05$. 

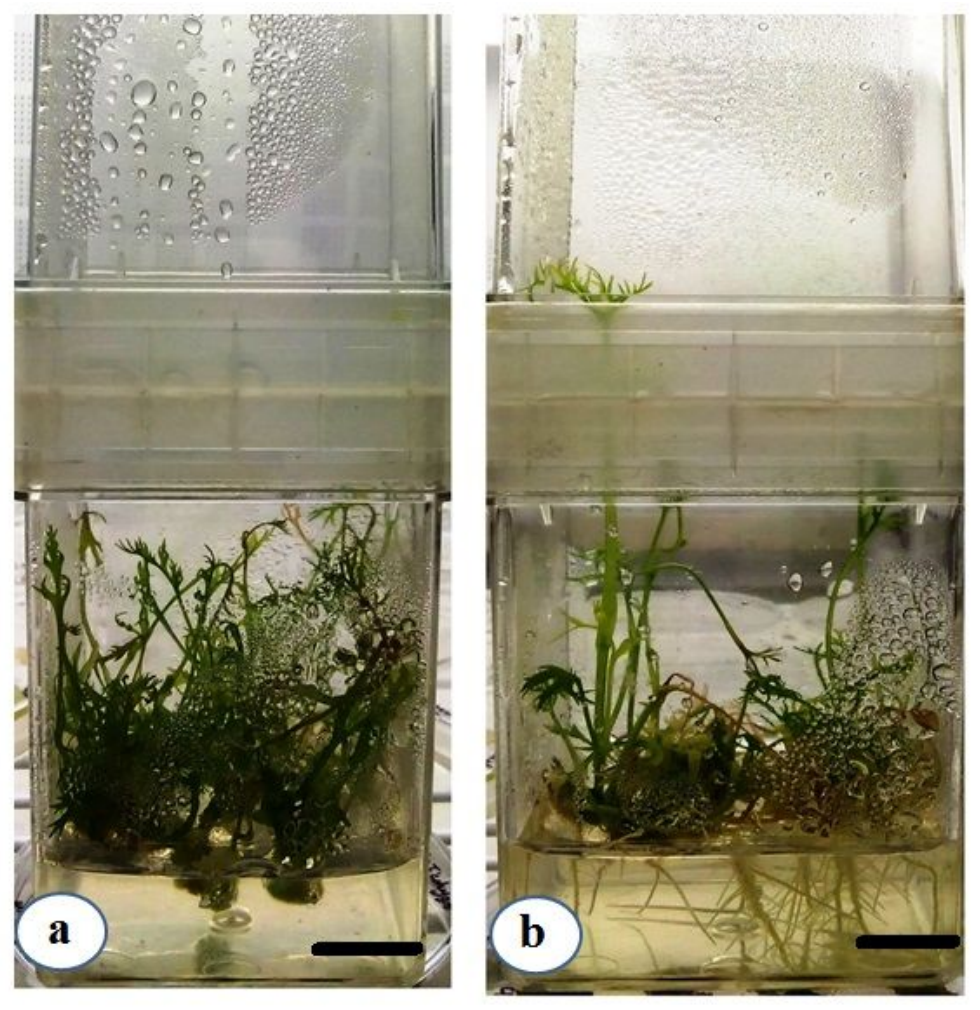

\section{Figure 3}

Root induction of in vitro regenerated shoots of ajowan. (a) Establishment of indirect regenerated shoot in half strength PGR-free MS medium (bar=3cm). (b) Well developed roots of indirect regenerated shoots after three weeks settling in root induction medium (bar=3cm). 

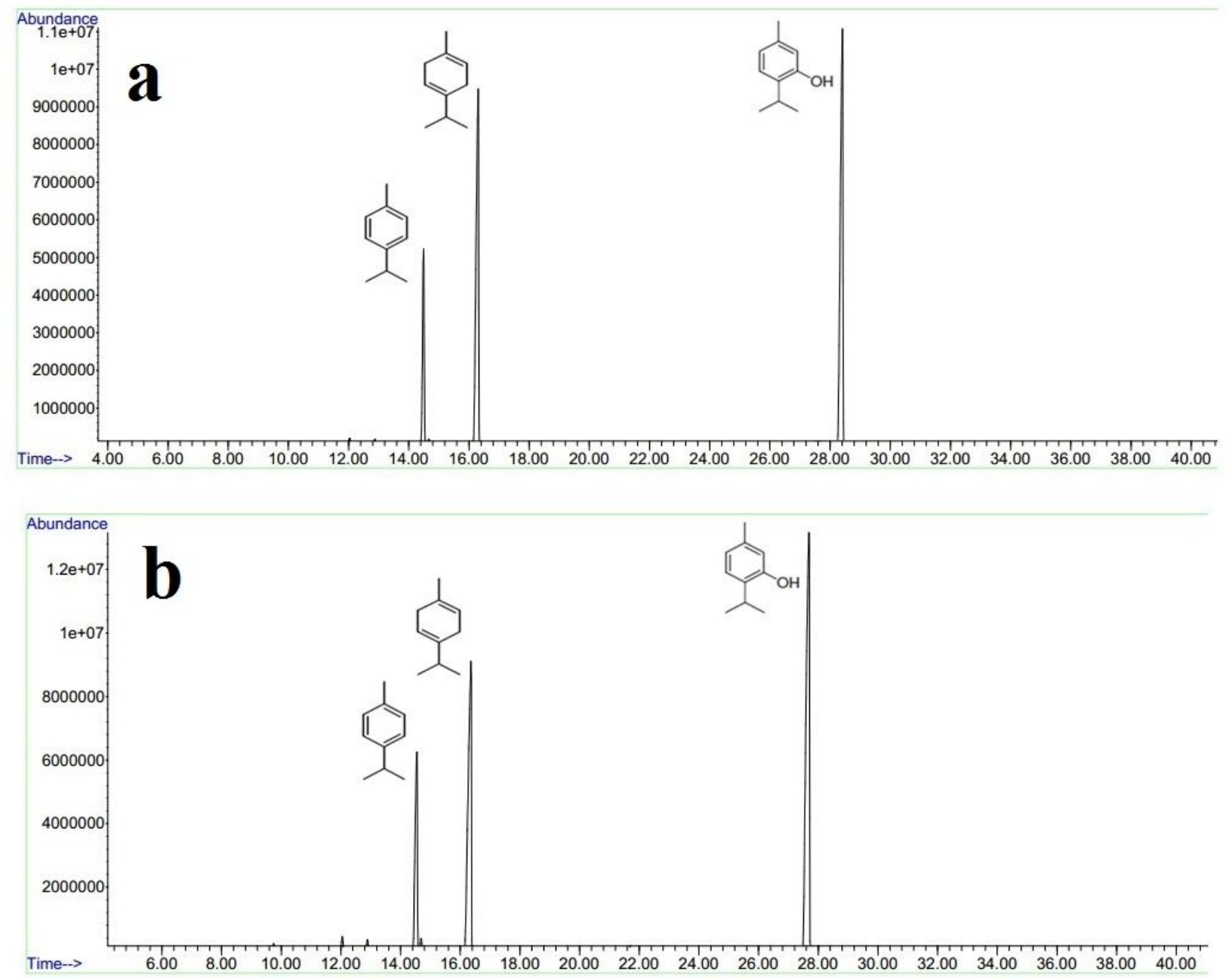

Figure 4

The GC-MS profiling of (a) in vitro regenerated in control and (b) in vitro regenerated under the effect of PEG and SA elicitors.

\section{$\begin{array}{llllllll}\text { T6 } & \text { T5 } & \text { T4 } & \text { T3 } & \text { T2 } & \text { T1 } & \text { C } & \text { M }\end{array}$}

Figure 5 
DNA fingerprinting pattern generated with UBC 815 ISSR primer. M: molecular weight marker; C: control plants; T1-T6: in vitro regenerated plants in MS medium supplemented with of Kin $(1.5 \mathrm{mg} / \mathrm{L})$ and NAA $(0.25 \mathrm{mg} / \mathrm{L})$ plant growth regulators and PEG and salicylic acid elicitors. 